\title{
A literatura e o necropoder: planos de fuga
}

\author{
Tiago Hermano Breunig ${ }^{1}$ \\ Universidade Federal de Pernambuco - UFPE, Recife, Pernambuco, Brasil
}

Resumo: $O$ presente trabalho procura propor uma relação entre a literatura e o conceito de necropoder, de Achille Mbembe. O conceito de necropoder serve como uma chave de leitura para compreender como, em ambientes que compartilham um passado colonial, a literatura pode problematizar as formas que o terror assume na contemporaneidade. 0 ensaio sugere que a literatura, situada no limiar entre a ficção e a realidade, problematiza a imaginação e as representações produzidas pela ocupação colonial que fundamentam o necropoder. Para tanto, reconstitui a genealogia do conceito criado por Mbembe e a constelação de conceitos em que gravita para, por fim, sugerir uma leitura do romance Rremembranças da menina de rua morta nua, de Valêncio Xavier. O romance, publicado em 2006, permite entrever a função decisiva da ficção diante dos fatos indissociados das fabulações do colonialismo e das novas relações entre os fatos e as ficções na civilização da imagem.

Palavras-chave: Necropoder; Achille Mbembe; Valêncio Xavier.

Title: Literature and necropolitics: escape plans

Abstract: This paper aims to propose a relationship between literature and Achille Mbembe's concept of necropolitics. The concept of necropolitics serves as a key to understanding how, in countries that share a colonial past, literature can problematize the forms that terror assumes in contemporaneity. The paper suggests that literature, situated on the threshold between fiction and reality, problematizes the imagination and the representations produced by the colonial occupation that underlie necropolitics. Therefore, it reconstructs the genealogy of the concept created by Mbembe and the constellation of concepts in which it gravitates to, at last, suggest a reading of the Brazilian novel Rremembranças da menina de rua morta nua, by Valêncio Xavier. The novel, published in 2006, allows us to glimpse the decisive role of fiction in face of facts, inseparable of the colonialist fabulations, and the new relationships between facts and fiction in the civilization of the image.

Keywords: Necropolitics; Achille Mbembe; Valêncio Xavier.

Achille Mbembe, ao tratar do continente africano descolonizado, menciona uma "vontade generalizada de fuga", um "irreprimível desejo, de centenas de milhões de pessoas, de viver em qualquer outro lugar do mundo que não o seu" (MBEMBE, 2014b, p. 23). Diante, no entanto, da falta de outro mundo e, portanto, da possibilidade de fuga, resta reinventar o

\footnotetext{
${ }^{1}$ Doutor em Literatura pela Universidade Federal de Santa Catarina - UFSC. Professor Adjunto do Departamento de Letras da Universidade Federal de Pernambuco - UFPE. Orcid: https://orcid.org/0000-0003-3123-3897 E-mail: tiago.breunig@ufpe.br
} 
mundo, contrapondo o mundo e o mundo porvir, ao modo, imaginemos, de uma fuga ou de uma composição fugal, que considere, como sugere Mbembe (2014b, p. 47), que "a reinvenção só é possível através da contemplação tanto do passado quanto do futuro". E a literatura, em um sentido oposto ao antigo tema da fuga, pode contribuir decisivamente para a reinvenção do mundo.

\section{O necropoder}

O conceito de necropoder de Mbembe se disseminou no Brasil de tal maneira que parece justo reconstituir a genealogia do conceito e a constelação de conceitos em que gravita, sobretudo se queremos estabelecer uma relação com a literatura. Afinal, a literatura não consta do horizonte de preocupações de Mbembe ao formular o conceito, mas parece produtiva, como procuraremos demonstrar, para compreender as formas que o terror assume em nossa contemporaneidade, com o desmantelamento do Estado e de suas instituições a partir, principalmente, da privatização, e com a mercantilização de todas as dimensões da sociedade.

Ao formular o conceito de necropoder, Mbembe retoma o tema da aula de Michel Foucault que trata do nascimento do racismo de Estado e em que se conceitua o biopoder. Na aula, de 17 de março de 1976, Foucault (1999, p. 285-286) apresenta "o que se poderia denominar a assunção da vida pelo poder":

uma tomada de poder sobre o homem enquanto ser vivo, uma espécie de estatização do biológico ou, pelo menos, certa inclinação que conduz ao que se poderia chamar de estatização do biológico. Creio que, para compreender o que se passou, podemos nos referir ao que era a teoria clássica da soberania que, em última análise, serviu-nos de pano de fundo, de quadro para todas essas análises sobre a guerra, as raças, etc. (FOUCAULT, 1999, p. 286).

Para compreender a "assunção da vida pelo poder", Foucault recupera o conceito de soberania. Um dos atributos fundamentais da soberania, explica Foucault (1999, p. 286), consiste no "direito de vida e de morte". Ao inscrever a vida e a morte no "campo do poder político" para explicar o conceito de soberania, Foucault $(1999$, p. 286) enuncia o direito que o sintetiza: "dizer que o soberano tem direito de vida e de morte significa, no fundo, que ele pode fazer morrer e deixar viver". Finalmente, Foucault (1999, p. 287) introduz o conceito de biopolítica ao constatar as "transformações do direito político do século XIX" em torno da soberania, ou seja, do "direito de matar" que sustenta "o direito de fazer morrer ou de deixar viver" do soberano. Para Foucault, a transformação fundamental consiste

em completar esse velho direito de soberania - fazer morrer ou deixar viver - com outro direito novo, que não vai apagar o primeiro, mas vai penetrá-lo, perpassá-lo, modificá-lo, e que vai ser um direito, ou melhor, um poder exatamente inverso: o poder de 'fazer' viver e de 'deixar' morrer. O direito de soberania é, portanto, o de 
fazer morrer ou de deixar viver. E depois, este novo direito é que se instala: o direito de fazer viver e de deixar morrer (FOUCAULT, 1999, p. 287).

Esse "novo direito" que se instala, anunciado como "o direito de fazer viver e de deixar morrer", define, assim, a biopolítica, que nomeia as técnicas de poder que se aplicam ao ser vivo enquanto espécie e se incumbem da população, sobrepondo-se, a partir do final do século XVIII, às técnicas de poder centradas no corpo individual que caracterizam o poder disciplinar dos séculos XVII e XVIII:

\begin{abstract}
que essa nova técnica de poder não disciplinar se aplica é - diferentemente da disciplina que se dirige ao corpo - a vida dos homens, ou ainda, se vocês preferirem, ela se dirige não ao homem-corpo, mas ao homem vivo, ao homem ser vivo; no limite, se vocês quiserem, ao homem-espécie. Mais precisamente, eu diria isto: a disciplina tenta reger a multiplicidade dos homens na medida em que essa multiplicidade pode e deve redundar em corpos individuais que devem ser vigiados, treinados, utilizados, eventualmente punidos. E, depois, a nova tecnologia que se instala se dirige à multiplicidade dos homens, não na medida em que eles se resumem em corpos, mas na medida em que ela forma, ao contrário, uma massa global, afetada por processos de conjunto que são próprios da vida, que são processos como o nascimento, a morte, a produção, a doença, etc. Logo, depois de uma primeira tomada de poder sobre o corpo que se fez consoante o modo de individualização, temos uma segunda tomada de poder que, por sua vez, não é individualizante mas que é massificante, se vocês quiserem, que se faz em direção não do homem-corpo, mas do homem-espécie. Depois da anátomo-política do corpo humano, instaurada no decorrer do século XVIII, vemos aparecer, no fim do mesmo século, algo que já não é uma anátomo-política do corpo humano, mas que eu chamaria de uma 'biopolítica' da espécie humana (FOUCAULT, 1999, p. 289).
\end{abstract}

Assim, se em Foucault a transformação do poder soberano para o biopoder se anuncia pela transformação do "fazer morrer ou deixar viver" em "fazer viver e deixar morrer", em Mbembe não se trata mais de "fazer morrer ou deixar viver" ou "fazer viver e deixar morrer", mas de definir quem pode viver e quem deve morrer. Mbembe propõe os conceitos de necropoder e necropolítica para interrogar o direito de matar e compreender a inscrição da vida, da morte e do corpo humano na ordem do poder, considerando o conceito de biopoder "insuficiente para explicar as formas contemporâneas de subjugação da vida ao poder da morte" (MBEMBE, 2016, p. 146). Afinal, o biopoder consiste no "poder de assegurar a vida" e "tem como objeto e como objetivo a vida", como explica Foucault (1999, p. 303), e Mbembe se pergunta sobre o sujeito e o objeto do direito de morte, bem como sobre as condições de sua implementação, substituindo, portanto, dos conceitos foucaultianos, o prefixo bio, vida, por necro, morte. Assim, Mbembe (2016, p. 125) se concentra nas "formas de soberania cujo projeto central não é a luta pela autonomia, mas 'a instrumentalização generalizada da existência humana e a destruição material de corpos humanos e populações'”.

Mas Mbembe (2016, p. 128) nota que, em Foucault, o biopoder "parece funcionar mediante a divisão entre as pessoas que devem viver e as que devem morrer", subdivisão da 
população feita pelo racismo que, em termos foucaultianos, consiste numa tecnologia destinada a permitir o exercício do biopoder, com a função de regular a distribuição da morte. E, de fato, ao tratar do racismo, Foucault praticamente elabora o que fundamenta o conceito de necropoder quando se pergunta sobre o aparente paradoxo do direito de matar (o "fazer morrer" da soberania que teoricamente deveria recuar com o biopoder, disciplinar e regulamentador): "Como exercer o poder da morte, como exercer a função da morte, num sistema político centrado no biopoder?". Foucault (1999, p. 304) responde:

\begin{abstract}
É aí, creio eu, que intervém o racismo. Não quero de modo algum dizer que o racismo foi inventado nessa época. Ele existia há muito tempo. Mas eu acho que funcionava de outro modo, o que inseriu o racismo nos mecanismos do Estado foi mesmo a emergência desse biopoder. Foi nesse momento que o racismo se inseriu como mecanismo fundamental do poder, tal como se exerce nos Estados modernos, e que faz com que quase não haja funcionamento moderno do Estado que, em certo momento, em certo limite e em certas condições, não passe pelo racismo.
\end{abstract}

Portanto, o racismo, enquanto promove a fragmentação do contínuo biológico da espécie humana pela distinção, hierarquização e qualificação de raças, permite o funcionamento do "velho poder soberano do direito de morte" no biopoder. Nesse contexto, o que possibilita o que Foucault chama de "poder de morte" parece estar uma condicional: "tirar a vida só é admissível, no sistema de biopoder, se tende [...] à eliminação do perigo biológico e ao fortalecimento da própria espécie ou da raça" (FOUCAULT, 1999, p. 306). Para tanto, o racismo é "a condição de aceitabilidade de tirar a vida numa sociedade de normalização", a "condição para que se possa exercer o direito de matar". E por "tirar a vida", explica Foucault (1999, p. 306), "não entendo simplesmente o assassínio direto, mas também tudo o que pode ser assassínio indireto: o fato de expor à morte, de multiplicar para alguns o risco de morte ou, pura e simplesmente, a morte política, a expulsão, a rejeição, etc."

Com efeito, a concepção de soberania se encontra na origem do conceito de necropolítica de Mbembe, em que ocupa um lugar central e não mais condicional, como em Foucault. Para Mbembe (2016, p. 123), "a expressão máxima da soberania reside, em grande medida, no poder e na capacidade de ditar quem pode viver e quem deve morrer", e em configurações de "ocupação colonial", em que "a exceção proporciona a estrutura da soberania", a soberania se revela como "a capacidade de definir quem importa e quem não importa, quem é 'descartável' e quem não é" (MBEMBE, 2016, p. 135). Como se nota, Mbembe mobiliza os conceitos de soberania e de estado de exceção aprofundados por Giorgio Agamben, que postula o estado de exceção como regra e o campo como paradigma do espaço político da modernidade. No entanto, Mbembe sobrepõe ao campo a colônia, propondo um paralelo entre a colonização e o estado de exceção, ou seja, o dispositivo tornado paradigma de governo que, pela suspensão indeterminada da lei, constitui, como explica Agamben (2004, p. 13), um "patamar de indeterminação entre democracia e absolutismo" ou "a forma legal daquilo que não pode ter forma legal" (AGAMBEN, 2004, p. 
12). Assim, Mbembe (2016, p. 133) conclui que "as colônias são o local por excelência em que os controles e as garantias de ordem judicial podem ser suspensos - a zona em que a violência do estado de exceção supostamente opera a serviço da 'civilização'".

Em Agamben encontramos outra formulação daquele "poder da morte" de que trata Foucault ao identificar uma sobrelevação da soberania no biopoder. Mas Agamben nomeia essa formulação: "tanatopolítica".

No mesmo passo em que se afirma a biopolítica, assiste-se, de fato, a um deslocamento e a um progressivo alargamento, para além dos limites do estado de exceção, da decisão sobre a vida nua na qual consistia a soberania. Se, em todo Estado moderno, existe uma linha que assinala o ponto em que a decisão sobre a vida torna-se decisão sobre a morte, e a biopolítica pode deste modo converter-se em tanatopolítica, tal linha não mais se apresenta hoje como um confim fixo a dividir duas zonas claramente distintas (AGAMBEN, 2010, p. 119).

No contexto "biopolítico (ou tanatopolítico)" que, afinal, não mais se distinguem claramente, o campo, segundo Agamben (2010, p. 119), emerge como paradigma: "Nesta perspectiva, o campo, como puro, absoluto e insuperado espaço biopolítico (e enquanto tal fundado unicamente sobre o estado de exceção) surgirá como paradigma oculto do espaço político da modernidade". E ao voltar a mencionar a tanatopolítica para circundar o "ponto em que a biopolítica converte-se necessariamente em tanatopolítica", Agamben (2010, p. 138) antecipa a ideia de que a soberania se trata de ditar quem importa e quem não importa, como veremos em Mbembe:

Se ao soberano, na medida em que decide sobre o estado de exceção, compete em qualquer tempo o poder de decidir qual vida possa ser morta sem que se cometa homicídio, na idade da biopolítica este poder tende a emancipar-se do estado de exceção, transformando-se em poder de decidir sobre o ponto em que a vida cessa de ser politicamente relevante. [...] Na biopolítica moderna, soberano é aquele que decide sobre o valor ou sobre o desvalor da vida enquanto tal (AGAMBEN, 2010, p. 138).

Ora, ao não assumir o conceito de tanatopolítica, de Agamben, como se o conceito se mostrasse igualmente insuficiente, e fundar o conceito de necropolítica, Mbembe parece redimensionar a questão do poder da morte a partir do colonialismo, do imperialismo colonial e das tecnologias de morte originadas com o escravismo moderno e o racismo, e aprimoradas com o neoliberalismo. Para Mbembe, o entendimento da modernidade deve conjugar o colonialismo e o escravismo com o capitalismo e o liberalismo, reconhecendo o imperialismo colonial, que inicia um longo processo de desumanização e industrialização da morte, como a premissa material, inclusive, para o racismo de Estado analisado por Foucault:

Esse processo foi, em parte, facilitado pelos estereótipos racistas e pelo florescimento de um racismo baseado em classe que, ao traduzir os conflitos sociais do mundo industrial em termos raciais, acabou comparando as classes 
trabalhadoras e os "desamparados pelo Estado" do mundo industrial com os "selvagens" do mundo colonial (MBEMBE, 2016, p. 129).

Embora Foucault identifique a colonização europeia na origem do racismo e na reprodução de seus mecanismos de poder no Ocidente, Mbembe (2014b, p. 105) observa que "ao abordar o estado racial em finais da década de 1970, Michel Foucault não despende uma única palavra com a África do Sul, que, no entanto, representa na época o único arquétipo 'realmente existente' da segregação legal'. A compreensão da modernidade em Mbembe se funda, portanto, no colonialismo e em suas instituições, de modo que

Qualquer relato histórico do surgimento do terror moderno precisa tratar da escravidão, que pode ser considerada uma das primeiras instâncias da experimentação biopolítica. Em muitos aspectos, a própria estrutura do sistema de colonização e suas consequências manifesta a figura emblemática e paradoxal do estado de exceção (MBEMBE, 2016, p. 130).

Para Mbembe, a divisão do trabalho na economia colonial não foi apenas uma das condições de crescimento do capitalismo industrial, mas formulou as "condições estruturais de troca desigual que, desde então, caracterizam as relações entre o centro e a periferia". Assim, as colônias "formariam elos essenciais do devir-mundo do capitalismo", conclui Mbembe (2014b, p. 51), constatando que a função do imperialismo colonial consistiu na implementação das condições estruturais de uma troca contrafeita e desigual entre o centro e a periferia, as quais perduram atualmente enquanto centro e periferia das cidades das sociedades descolonizadas, tornando ainda mais complexa "a delimitação das fronteiras internas e externas" (MBEMBE, 2014b, p. 80).

As fronteiras do "imenso abismo" (MBEMBE, 2014b, p. 19) aberto e encoberto pelo colonialismo e aprofundado pelo neoliberalismo fratura não apenas o mundo descolonizado, mas o ser humano. Afinal, como constata Mbembe (2014b, p. 68), o capitalismo colonial se apropria economicamente da "esfera do vivo", produzindo, na idade e do ponto de vista do neoliberalismo, uma "classe de 'supérfluos'" que "representam carne humana subjugada à lei do desperdício, da violência e da doença" (MBEMBE, 2014b, p. 26). Ao mesmo tempo, emerge o "novo ser humano" da "civilização da imagem e das novas relações que ela estabelece entre os fatos e as fiç̧ões" (MBEMBE, 2014a, p. 14), cuja solubilidade e descartabilidade o aproxima da condição de mercadoria imposta pela escravidão, de modo que os riscos "aos quais os escravos negros foram expostos durante o primeiro capitalismo constituem agora, se não a norma, pelo menos o quinhão de todas as humanidades subalternas" (MBEMBE, 2014a, p. 15-16).

Naquelas cidades, fraturadas pela ocupação colonial, em que opera o necropoder, a soberania constitui, como vimos, "a capacidade de definir quem importa e quem não importa, quem é 'descartável' e quem não é" (MBEMBE, 2016, p. 135). E, para tanto, a imaginação produzida pela ocupação colonial exerce um papel fundamental, pois legitima a "instituição de direitos diferentes, para diferentes categorias de pessoas, para fins 
diferentes" dentro do conjunto de relações sociais e espaciais instauradas pela ocupação colonial (MBEMBE, 2016, p. 135). A fratura provocada pelo colonialismo europeu permanece atrelada a suas fantasias e suas ficções, de modo que a "colonização é indissociável das construções imaginárias e das representações simbólicas e religiosas através das quais o pensamento ocidental figurou o horizonte terreno" (MBEMBE, 2014b, p. 75).

Se a ficção produzida pelo colonialismo fundamenta o necropoder, demasiado real para o Outro, e o sujeito do humanismo e do universalismo colonial é um "sujeito para o qual a riqueza é, sobretudo, um instrumento de exercício de vida e de morte sobre os outros", o humanismo e o universalismo acobertando a "força necropolítica que, ao transitar pela ficção, adoece com a vida, ou ainda, num ato de reversão permanente, toma a morte pela vida e a vida pela morte" (MBEMBE, 2014b, p. 69), então a ficção tem uma função decisiva diante dos fatos, indissociados, na verdade, das fabulações do colonialismo, bem como diante das novas relações entre os fatos e as ficções da nossa civilização da imagem.

Para tanto, a literatura apresenta funções divergentes ${ }^{2}$ e diferentes caminhos. Isabela Figueiredo, por exemplo, em suas recordações coloniais, em que parece comparar o pai, com sua racionalidade de colonizador europeu, a Portugal, descobre o necropoder pelo "nada" na literatura lida, ao mesmo tempo que o evidencia pela literatura. Ao estabelecer a mesma comparação entre o estado de exceção normalizado como campo e a colonização proposta por Mbembe, recorda que a "terra justa" dos seus livros de literatura mostrava "que na terra onde vivia não existia redenção alguma", que "era um enorme campo de concentração de negros sem identidade, sem a propriedade do seu corpo". "Nada nos meus livros, que recorde, estava escrito desta exata forma, mas foi o que li!" (FIGUEIREDO, 2018, p. 45-46), conclui a narradora, evidenciando, ao seu modo, o abismo entre a Europa e suas ocupações coloniais e, nestas, entre europeus e africanos. O abismo, enfim, entre o humanismo proclamado pela razão ocidental e suas decisões. "Sem matar o 'pai', impregna-o de uma culpabilidade que induz um arrependimento", diria Mbembe (2014b, p. 67) acerca da literatura africana, que visa, segundo o autor, justamente libertar o sujeito do nada ao qual foi confinado pelo colonialismo.

Mas, para tanto, a literatura precisa de um amparo: "a reflexão crítica acerca das formas contemporâneas de instrumentalização da vida pode reforçar a sua radicalidade, caso se proponha a encarar com seriedade essas formações antigas e recentes do capitalismo, como a escravatura e a colonização", afirma Mbembe (2014b, p. 67-68). Nesse sentido, a crítica pós-colonial

tenta desconstruir a prosa colonial, ou seja, a montagem mental, as representações e as formas simbólicas que servem de infraestrutura ao projeto imperial. Procura desmascarar o poderio de falsificação - em suma, a reserva de falsidade e as funções de fabulação sem as quais o colonialismo teria fracassado enquanto

\footnotetext{
2 Ainda em ensaio de 1966, Antonio Candido (1989) reconhecia que a literatura no Brasil foi, enquanto expressão da cultura colonialista, parte do processo colonizador, desempenhando uma função importante no processo de imposição cultural e, a seguir, de problematização das desarmonias da colonização.
} 
configuração histórica de poder (MBEMBE, 2014b, p. 68).

\section{E a literatura: Rremembranças da menina de rua morta nua, de Valêncio Xavier}

Considerando sua função diante da relação entre os fatos e as ficções do colonialismo, aprofundada pela civilização da imagem, a literatura que olha mais detidamente para o abismo do colonialismo e, portanto, do capitalismo, em suas passadas e presentes formações, parece ser a que se situa no limiar entre a fiç̧ão e a realidade. Dali, do limiar entre a ficção e a realidade, a literatura pode problematizar a imaginação que, como vimos, legitima o necropoder, e o longo processo de desumanização promovido pelo imperialismo colonial, estimulando uma leitura da modernidade fundamentada nas categorias da vida e da morte em detrimento da razão ocidental como categoria da verdade do sujeito.

Figura 1

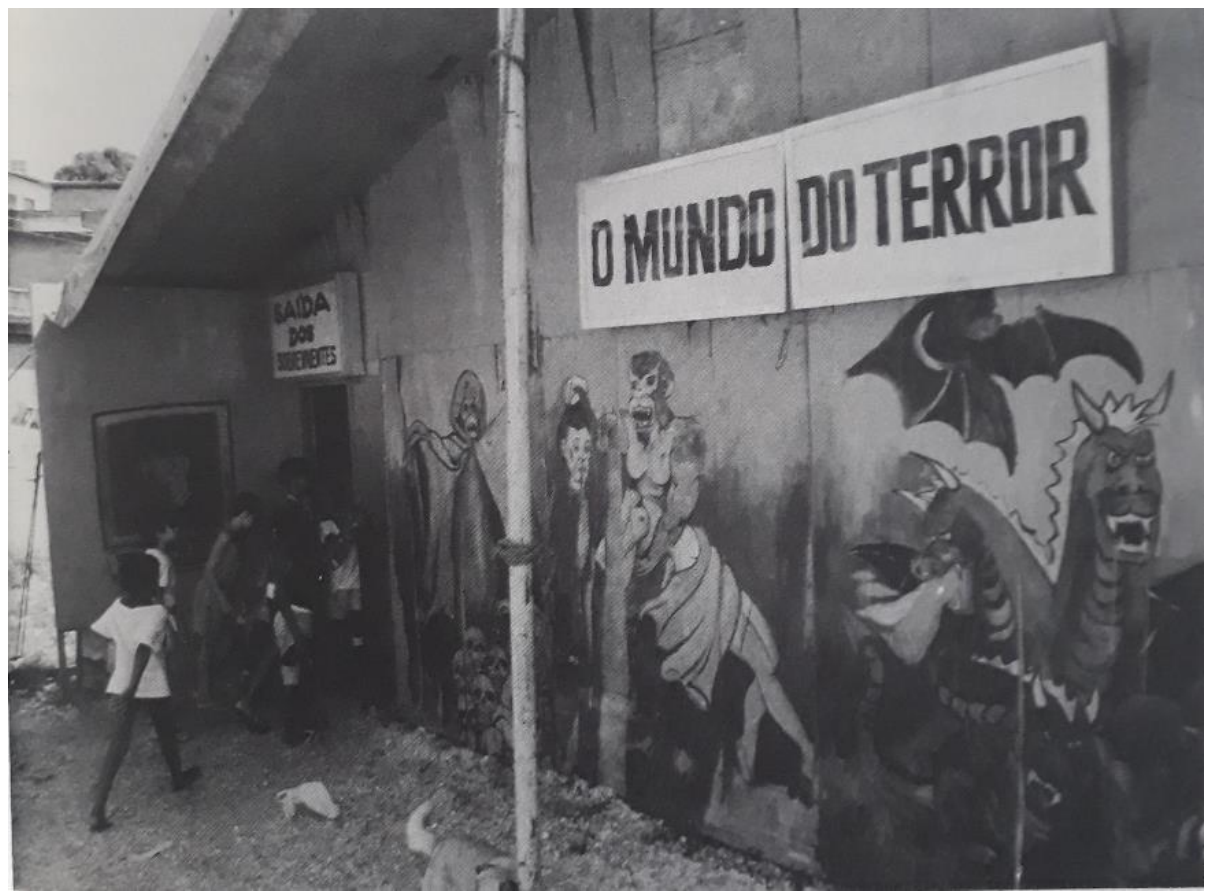

Fonte: XAVIER, 2006, p. 51.

Situada precisamente no limiar entre a ficção e a realidade, a literatura de Valêncio Xavier permite indagar a relação entre a formação peculiar do terror que $\operatorname{Mbembe}(216, p$. 136) chama de necropoder, dinamizado pela "fragmentação territorial", e as "fantasias geradas colonialmente, caracterizadas por terras selvagens, morte e ficções para criar um efeito de real" (MBEMBE, 2016, p. 134). A partir do recorte de imagens e de textos de diferentes esferas discursivas, especialmente factuais, deslocados de seus suportes, o 
procedimento de montagem de sua narrativa contribui para desmontar a "montagem mental" que, tendo servido de "infraestrutura ao projeto imperial" (MBEMBE, 2014b, p. 68), permanece sustentado o capitalismo neoliberal.

Figura 2

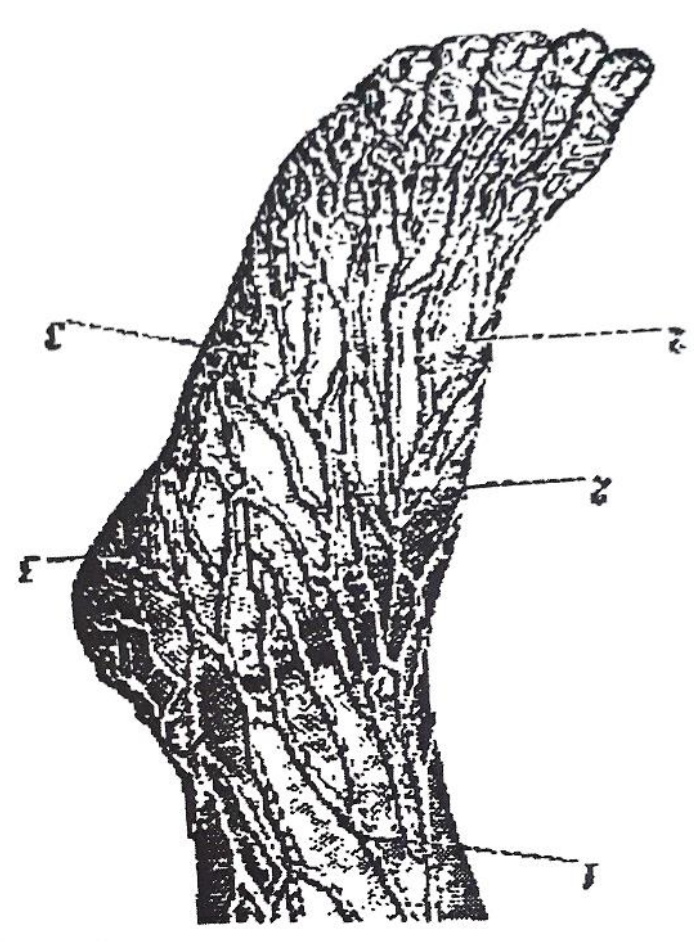

"Quando nós abrimos um dos caixões, apareceu um pé da garota morta e saímos correndo para avisar os donos do parque", contaram os dois na polícia. O corpo de estava em decomposição, e próximo ao caixão foram encontradas as suas roupas. Ela tinha um grande ferimento na cabeça.

Fonte: XAVIER, 2006, p. 53.

Em Rremembranças da menina de rua morta nua, por exemplo, a rememoração dos acontecimentos pela montagem de restos, inclusive mortais, destinados ao esquecimento, preserva algo do passado a ser lembrado e, sobretudo, desenterra no presente o que permanece, escondido ou esquecido, do passado, pela concatenação de membros aparentemente desmembrados, de forma a remembrar, ou seja, rememorar os mortos, bem como a nossa insensibilidade para a morte dos outros: 


\title{
Figura 3
}

\author{
Lembrar, v. Do lat. memorare, <lembrar, con- \\ tar, mencionar; fazer menção de, falar a \\ respeito de; lembrar que $>$. Houve as fases \\ intermediárias: membrar e nembrar 1. Da \\ primeira que parece ter-se arcaizado cedo, \\ só conheço esta abonação do séc. XIII: \\ $<$ e, pero era menyno, | rremembra-me que \\ foi assi>, Afonso X, o Sábio, Cantigas de \\ Santa Maria, № 256, em J. J. Nunes, Cres- \\ tonacia Arcaica, p. 423, $2^{\mathrm{a}}$ ed. Nembrar \\ na mesma época: $<$ Des que a non vi, no \\ er vi pesar | $D$ al, ca nunca mi d al pudi \\ nembrar>, D. Dinis, no C. B. N., № [468] \\ Dicionário Etymológico da Língua \\ Portuguesa de José Pedro Machado
}

Fonte: XAVIER, 2006, p. 42.

A concatenação entre o membro do corpo visto pelas testemunhas e as formas arcaicas do verbo "lembrar", como "membrar", cujo recurso constitui um procedimento recorrente no romance, indica, portanto, o modo de operar da narrativa de Xavier e o tema do romance: lembrar e narrar. Assim, formas arcaicas nos fragmentos de antigos textos portugueses de autoria de Duarte I, Rei de Portugal, e Camões, ambos, ao seu modo, relacionados ao colonialismo, sugerem que, sob o acontecimento narrado, formas arcaicas do capitalismo, como a colonização e a escravidão, permanecem, esquecidas, na formação da sociedade brasileira moderna. Ambos os fragmentos, em que se presentificam formas arcaicas do verbo "lembrar", encontradas no verbete acima, tratam do mesmo tema:

Figura 4

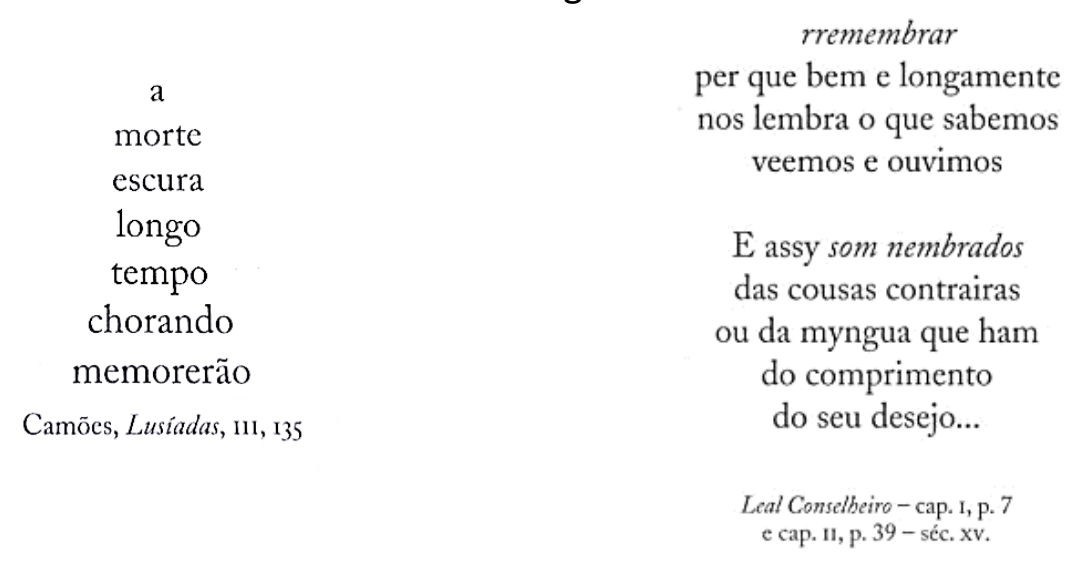

Fonte: XAVIER, 2006, p. 56 e 58.

De Camões, Xavier recorta um segmento dos primeiros versos da estrofe 135 do canto terceiro de sua epopeia, que reconstitui a genealogia real de Portugal, dispondo as palavras verticalmente umas sobre as outras. E de Duarte I, organiza, em forma de verso, dois fragmentos do seu tratado de moral escrito em prosa. O fragmento de Camões trata da 
conservação de um acontecimento, uma "morte escura", pela rememoração e monumentalização "em fonte pura" (CAMÕES, 1979, p. 143) de uma vida assassinada pelo poder soberano do rei, contrastando, como nota Pascoal Farinaccio (2013, p. 174), com "a descartabilidade do discurso televisivo, que noticia ao mesmo tempo em que condena ao esquecimento a morte da menina de rua". O fragmento de Duarte I, por sua vez, trata da parte do nosso entendimento que consiste em relembrar o que aprendemos (DOM DUARTE, 1843, p. 6) e da necessidade de lembrar o que contraria os nossos desejos (DOM DUARTE, 1843 , p. 34). A reunião dos membros em um outro corpo, o texto, por meio de um remembramento, permite, portanto, lembrar o que sabemos, vemos e ouvimos e, assim, o que não desejamos lembrar.

Ao evidenciar a espetacularização da morte pelo sensacionalismo das "imagens da televisão brasileira que caminham para o limbo do esquecimento", destinadas ao entretenimento das camadas populares e das "outras camadas sociais", mais precisamente a "elite" (XAVIER, 2006, p. 40), o romance problematiza a insensibilidade da sociedade e sua incapacidade de enterrar e rememorar os seus mortos. A espetacularização da morte da menina de rua pelos meios de comunicação se resume em entretenimento, ao modo de uma fiç̧ão policial e, ao mesmo tempo, de um terror. Um terror, no entanto, factual e indissociado da "formação peculiar de terror" instaurada em ocupações coloniais cujo funcionamento coincide, na idade do "terror moderno", com o necropoder. A espetacularização da morte da menina de rua depende de uma desafeç̧ão em relação a determinadas vidas, objetificadas, e de uma pulsão de morte. Assim, ao desvendar a relação entre a morte e o erotismo, o gozo com a morte e a (auto) destruição, a literatura sugere uma relação entre o necropoder e, figuradamente, a necrofilia da sociedade brasileira.

Figura 5

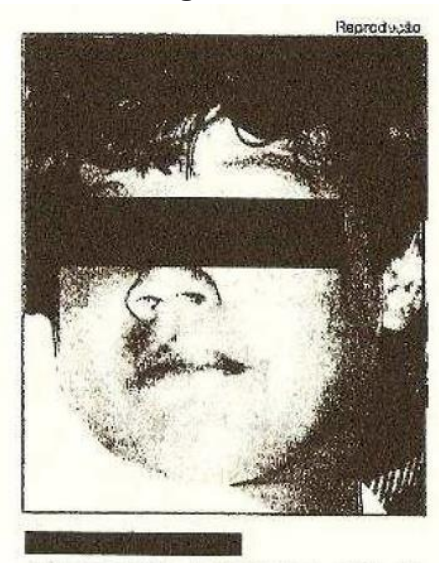

Fonte: XAVIER, 2006, p. 42.

No romance, a morte se depreende, inclusive, a partir do mesmo procedimento com as formas arcaicas das palavras, da etimologia da palavra imagem. E na imagem, repetida no romance, as tarjas pretas que encobrem os olhos e o nome da menina de rua morta parecem 
sugerir uma invisibilidade e uma substitutibilidade. Ora, a "reconstituição de um sujeito dotado de rosto, voz e nome", exige, como nota Mbembe (2014b, p. 50), em outro contexto, apropriado, no entanto, para a menina de rua morta nua, sem rosto, sem voz e sem nome, "um enorme trabalho epistemológico, e mesmo estético". Para tanto, argumenta Mbembe (2014b, p. 47), "a luta pelo afastamento em relação a uma ordem inumana das coisas não pode prescindir daquilo que se poderia apelidar de produtividade poética da memória e do religioso".

\begin{abstract}
O trabalho de memória é, neste caso, inseparável da reflexão sobre o modo de transformar a destruição física daqueles que se perderam e se transformaram em pó numa presença interior. Meditar sobre essa ausência e sobre os meios de recuperar simbolicamente o que foi destruído consiste, em grande medida, conferir à sepultura toda a sua força subversiva. Porém, neste caso, a sepultura não é tanto a celebração da morte em si, mas antes o retorno a esse complemento de vida necessário à elevação dos mortos, no seio de uma cultura nova que procura atribuir um lugar, quer para os vencedores quer para os vencidos (MBEMBE, 2014, p. 48)
\end{abstract}

As "rremembranças" consistem, portanto, em rememorar e enterrar, simbolicamente e subversivamente, a "menina de rua morta nua" que, ademais, representa a "vida nua". A vida "despojada de todo direito" que, como constata Agamben (2002, p. 189), pode ser morta, como as chamadas "minorias" que, hoje, parecem incorporar a condição de não reconhecimento como sujeito de direito de quem, no passado, a legislação brasileira categorizou como "menor".

\title{
Figura 6
}

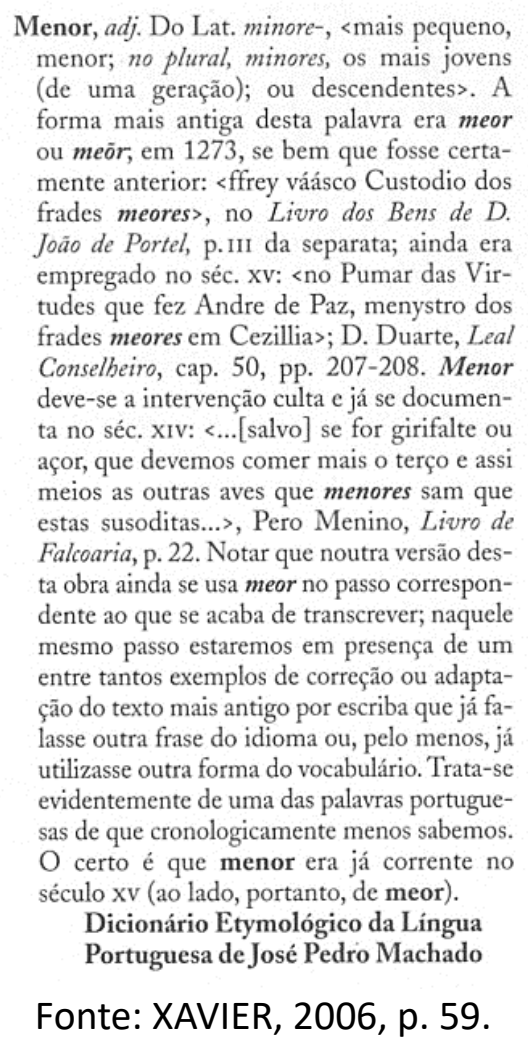


Ao remeter ao necropoder e a uma rearticulação para a qual a literatura oferece uma contribuição fundamental, como sugerimos, Mbembe aponta um caminho para "um novo pensamento da democracia" que nos interessa, embora se refira ao continente africano:

rearticulando, por exemplo, a política e o poder à volta da crítica das formas de morte ou, mais precisamente, do imperativo de alimentar as 'reservas de vida', poder-se-ia abrir caminho para um novo pensamento da democracia, num continente onde o poder de matar permanece mais ou menos ilimitado, e onde a pobreza, a doença e os perigos de todos os tipos tornam a existência incerta e precária (MBEMBE, 2014b, p. 25).

E nos interessa porque, afinal, o continente africano descrito por Mbembe habita o Brasil em sua geografia historicamente fraturada pelo abismo social e em cada corpo considerado sem valor, razão pela qual o conceito de necropoder se disseminou no Brasil.

\section{Referências}

AGAMBEN, Giorgio. Estado de exceção. Trad. Iraci D. Poleti. São Paulo: Boitempo, 2004.

AGAMBEN, Giorgio. Homo sacer: o poder soberano e a vida nua I. Trad. Henrique Burigo. 2. ed. Belo Horizonte: Editora UFMG, 2002.

CAMÕES, Luís de. Os lusíadas. São Paulo: Abril Cultural, 1979.

CANDIDO, Antonio. Literatura de dois gumes. In: A educação pela noite e outros ensaios. São Paulo: Ática, 1989.

DOM DUARTE. Leal Conselheiro e livro da ensinança de bem cavalgar toda sella. Lisboa: Typographia Rollandiana, 1843.

FARINACCIO, Pascoal. Valêncio Xavier: fotografando a morte. Cadernos benjaminianos, Belo Horizonte, n. 7, p. 165-176, dez. 2013.

FIGUEIREDO, Isabela. Caderno de memórias coloniais. São Paulo: Todavia, 2018.

FOUCAULT, Michel. Em defesa da sociedade: curso no Collège de France (1975-1976). São Paulo: Martins Fontes, 2005.

MBEMBE, Achille. Crítica da razão negra. Trad. Marta Lança. Lisboa: Antígona: 2014a.

MBEMBE, Achille. Necropolítica. Arte e ensaios: revista do PPGAV/EBA/UFRJ, Rio de Janeiro, n. 32, p. 123-151, dez. 2016.

MBEMBE, Achille. Sair da grande noite: ensaio sobre a África descolonizada. Trad. Narrativa Traçada. Luanda: Mulemba, 2014b. 